\title{
Probabilistic assessment of impacts of real-time line ratings on distribution networks
}

Link to publication record in Manchester Research Explorer

\section{Citation for published version (APA):}

Buhari, M., \& Kopsidas, K. (2014). Probabilistic assessment of impacts of real-time line ratings on distribution networks. In Probabilistic Methods Applied to Power Systems (PMAPS): 2014 International Conference (pp. 1-6). IEEE.

\section{Published in:}

Probabilistic Methods Applied to Power Systems (PMAPS)

\section{Citing this paper}

Please note that where the full-text provided on Manchester Research Explorer is the Author Accepted Manuscript or Proof version this may differ from the final Published version. If citing, it is advised that you check and use the publisher's definitive version.

\section{General rights}

Copyright and moral rights for the publications made accessible in the Research Explorer are retained by the authors and/or other copyright owners and it is a condition of accessing publications that users recognise and abide by the legal requirements associated with these rights.

\section{Takedown policy}

If you believe that this document breaches copyright please refer to the University of Manchester's Takedown Procedures [http://man.ac.uk/04Y6Bo] or contact uml.scholarlycommunications@manchester.ac.uk providing relevant details, so we can investigate your claim.

\section{OPEN ACCESS}




\section{Probabilistic Assessment of Impacts of Real-time Line Ratings on Distribution Networks}

\author{
Muhammad Buhari \\ Electrical Energy and Power Systems Group \\ University of Manchester \\ UK \\ muhammad.buhari@postgrad.manchester.ac.uk
}

\author{
Kostantinos Kopsidas \\ Electrical Energy and Power Systems Group \\ University of Manchester \\ UK \\ k.kopsidas@manchester.ac.uk
}

\begin{abstract}
Underground cabling systems which includes cables and ducts play a vital role in the planning and assessment of electro-thermal coordination that will incorporate smart energy transmission and utilize the prevailing weather conditions in implementing future smart distribution systems. This paper investigates the effects of increased adequacy through real-time line thermal ratings on network losses and risk of ageing. The analysis is performed on a range of underground cable duct installation methods in a distribution network. The paper proposes a new technique of assessing the reliability of distribution systems when real-time line rating is implemented on power cables considering the ducting methods and accounting for the reliability risks of cable ageing. Probabilistic assessments on nine different ducting installations for a buried 22kV XLPE cable showed that an oil pressure type cable ducting has the lowest risk of asset ageing when real-time line rating is implemented on the network.
\end{abstract}

Keywords-cable ducting, conductor temperatures, line losses, reliability assessment, thermal ratings, underground cables.

\section{INTRODUCTION}

Underground power cable (UGC) assets are receiving increasing interest regarding their operational reliability and identifying methods to estimate their ageing and its consequences on power network performance.

The loading current in a UGC is directly proportional to the cable temperature profile and it is used to estimate the cable thermal stresses along with soil temperature and other installation conditions. UGC ampacity and operating temperature are affected by factors such as cable size and thermal resistance, installation depth, ducting, and soil temperature and thermal resistance.

To increase mechanical protection and more importantly allow more circuits to share a common trench, UGCs are often installed in duct banks. These duct systems are made of different types of materials having different thermal resistivity from the surrounding native soil affecting the heat dissipation and in extension the ampacity of the buried cable. Total thermal resistance of the cabling system is also affected by the characteristics of the backfill, installation depth, the position of the cables as well as the instantaneous load profile [1].

Considering all the aforementioned cabling system parameters maximum operating thermal ratings are imposed to avoid excessive loading which could severely affect cable's operating characteristics [2]. Furthermore, these thermal ratings also affect the cable resistance and the accompanying resistive conductor heating which is recorded as Joule losses $[2,3]$. Joule losses are important in distribution systems since they form part of the energy generation costs and cable utilization costs. The latter is evident from the well-known Arrhenius equation, which describes the power cable deterioration/aging acceleration under increased thermal stresses.

Consequently, knowing the conductor operating temperature history is crucial in evaluating the aging of the cables and lines. In fact conductor temperature at certain conditions can constitute a reliability risk and needs to be considered and recorded. Several techniques have been developed for estimating conductor temperature, the most common ones been Finite element methods (FEM) [4], Finite difference methods (FDM) [5], step response method and Thermo electric equivalents (TEE) $[6,7]$. The TEEs is found to be computationally fast and accurate and hence is utilised in this paper particularly when considering the large number of cables and amount of simulations examined.

Knowing the instantaneous load profile is equally important as knowing the weather parameters of each component in order to identify the actual operating temperature history and therefore being able to determine the cable ageing. Therefore, real-time line ratings or time varying thermal ratings (TVTR) have been investigated by different researchers [3, 6-8]. However, studies have mainly focussed on overhead lines as a single component with limited considerations on the impacts on an entire system. There is one study that examines the impact of DTR on wide network performance but dwells on bare overhead lines in transmission systems [18]. Furthermore, studies considering the loadability levels, which the operator can implement during contingent situations, consider "pseudo TVTR" which is based on current instead of temperature as the limiting parameter and ignore the heat capacity of the component.

Probabilistic assessment methods and risk analysis during contingent situations have been successfully utilized to examine the relative merits of alternative schemes for distribution networks planning and operation. This also includes cases without any reinforcements [10-14]. Probabilistic network analysis is used to identify the risk of 
feeder failures based on acceptable maximum power interruptions in a year due to cable repairs and in order to develop a cable replacement policy [14]. Another study utilises the cable failure risk based on the contribution of a cable failure probability and the expected energy loss of the failure [13]. However, in most cases analyses do not consider the plant properties but rather only the fixed cable properties.

This paper proposes a method for assessing the operational reliability of a network by utilizing network's operating loading profiles and properties along with network's components properties. The use of this methodology allows assessing the reliability of a cabled distribution network based on a proposed risk of cable ageing index (RCAI). The overall goal is to provide a new reliability assessment technique that allows evaluating the status of most critical cables of the network assuming an all cables distribution network based on temperatures rather than currents for planning decisions.

\section{DISTRIBUTION NETWORK AND CABLE SYSTEM MODELLING}

\section{A. Studied Network}

The IEEE 33 bus network together with its default parameters and loads is used as the test network for the study [15]. The MV test system consists of 33 buses, 37 lines; with $22 \mathrm{kV}$ base voltage and 100MVA base. The peak load of the distribution network is $2.3 \mathrm{MW}$. Bus 1 is connected to a grid which supplies the connected loads. The default network is assumed to have $1 \mathrm{pu}$ of the original load values. The conventional IEEE RTS-24 load profile was used as the hourly chronological load profile as it is more detailed. The IEEE 33 bus network is shown in Fig. 1 indicating the cable resistances in three different levels (low, medium and high) as well as the loads (kW, kVAr) on each bus.

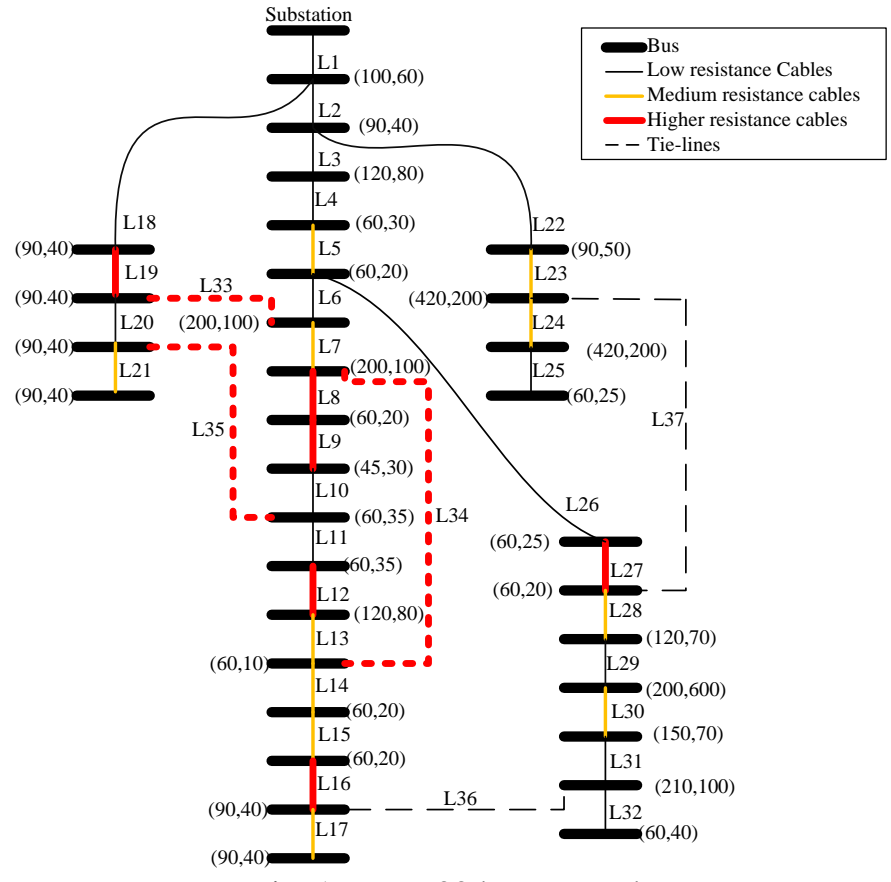

Fig. 1: IEEE 33 bus network

\section{B. Cable Thermal Model}

The thermal model from [16] is used to calculate the ampacity of the power cable for the condition of: buried cable without soil drying out, as shown in equation (1). All parameters are defined in Table I as discussed in [15].

$$
I=\sqrt{\frac{\left(\theta_{c}-\theta_{s}\right)-W_{d}\left[0.5 T_{1}+n\left(T_{2}+T_{3}+T_{4}\right)\right]}{R_{\theta} T_{1}+n R_{\theta}\left(1+\lambda_{1}\right) T_{2}+n R_{\theta}\left(1+\lambda_{1}+\lambda_{2}\right)\left(T_{3}+T_{4}\right)}}
$$

In this paper, the thermal model of a 3 phase UGC having, $22 \mathrm{kV} 95 \mathrm{~mm}^{2}$ aluminium conductor, $25 \mathrm{~mm}^{2}$ copper screen, XLPE insulation, is used for the branch cables, which is used for each of the 37 lines of the 33 bus distribution network for operating temperatures of up to $90^{\circ} \mathrm{C}$ with soil ambient condition ( $\theta_{s}$ ) ranging between 3 to $16^{\circ} \mathrm{C}$ in the UK [20]. The cable diameter is $64 \mathrm{~mm}$ and the duct outside and inside diameter is $110 \mathrm{~mm}$ and $95 \mathrm{~mm}$ respectively. The conductor diameter is $12 \mathrm{~mm}$ with an insulation diameter (excluding screen) of $28 \mathrm{~mm}$. The cables are in trefoil formation with 30 $\mathrm{mm}$ axial separation between conductor axis at a depth of 800 $\mathrm{mm}$. The thickness of the cable PVC serving is $3 \mathrm{~mm}$. Table I shows the common cable quantities used for the cable thermal model assuming uniform thermal properties for all cable materials

TABLE I

XLPE CABLE THERMAL RATING PARAMETERS [19]

\begin{tabular}{|l|l|l|}
\hline Parameter & Definition & value \\
\hline$\Delta \theta$ & $\begin{array}{l}\text { Conductor temperature rise above } \\
\text { ambient }\end{array}$ & up to $74^{\circ} \mathrm{C}$ \\
\hline $\mathbf{W}_{\mathbf{d}}$ & $\begin{array}{l}\text { Dielectric loss per unit length per } \\
\text { phase }\end{array}$ & $0.088987 \mathrm{~W} / \mathrm{m}$ \\
\hline $\mathbf{T}_{\mathbf{1}}$ & $\begin{array}{l}\text { Thermal resistance per core } \\
\text { between conductor and sheath }\end{array}$ & $0.908 \mathrm{~K} \mathrm{~m} / \mathrm{W}$ \\
\hline $\mathbf{T}_{\mathbf{2}}$ & $\begin{array}{l}\text { Thermal resistance between } \\
\text { sheath and armour }\end{array}$ & $0 \mathrm{~K} \mathrm{~m} / \mathrm{W}$ \\
\hline $\mathbf{T}_{\mathbf{3}}$ & $\begin{array}{l}\text { Thermal resistance of external } \\
\text { serving }\end{array}$ & $0.0986 \mathrm{~K} \mathrm{~m} / \mathrm{W}$ \\
\hline $\mathbf{R}_{\mathbf{s c}}$ & Cable screen resistance & $0.00089808 \Omega / \mathrm{m}$ \\
\hline $\mathbf{n}$ & Number of cores & 3 \\
\hline$\lambda_{1}$ & Loss factor for screen/sheath & $8.12 \mathrm{E}-05$ \\
\hline$\lambda_{2}$ & Loss factor for armour & 0 \\
\hline
\end{tabular}

\section{Cable Ducting Systems}

The paper considers the properties of the ducting used as part of the cable system and therefore different reliability evaluation studies using nine different cable duct installations are considered. Table II illustrates the ratings of the most critical loaded cables in the IEEE network considering a $90^{\circ} \mathrm{C}$ conductor temperature and a $16^{\circ} \mathrm{C}$ soil temperature based on the different ducting conditions. From Table II it is evident that the thermal resistance of the cables' surrounding medium has a huge influence on the cable ampacity [1]. The duct installations of [2] are used and listed below and labelled C1 to $\mathrm{C} 9$ for simplification.

$\mathrm{C} 1$ : Use of metallic conduits 
C2: Fibre duct in air exposed cables

C3: Fibre duct in a concrete duct bank

C4: Asbestos cement in air exposed cables

C5: Asbestos cement in concrete duct bank

C6: Gas pressure pipe type cables

C7: Oil pressure pipe type cables

C8: Plastic ducts in concrete duct bank and

C9: Earthenware ducts

TABLE II

XLPE CABLE THERMAL RATINGS AT $90^{\circ} \mathrm{C}$ WITH $16^{\circ} \mathrm{C}$ SOIL TEMPERATURE

\begin{tabular}{|l|c|ccc|}
\hline \hline $\begin{array}{l}\text { Ducting } \\
\text { installation } \\
\text { condition }\end{array}$ & $\mathbf{T}_{\mathbf{4}}(\mathbf{K ~ m} / \mathbf{W})$ & \multicolumn{3}{|c|}{ Ampacity $(\mathrm{A})$ of the most critical cables } \\
\cline { 3 - 5 } & & $\begin{array}{c}\text { Low } \\
(0.00493 \Omega)\end{array}$ & $\begin{array}{c}\text { Medium } \\
(0.00898 \Omega)\end{array}$ & $\begin{array}{c}\text { High } \\
(0.01540 \Omega)\end{array}$ \\
\hline C1 & 1.2596 & 54.7 & 40.5 & 31.3 \\
C2 & 1.5255 & 51.0 & 37.8 & 29.2 \\
C3 & 1.4235 & 52.5 & 38.9 & 30.0 \\
C4 & 1.3577 & 54.2 & 40.1 & 31.0 \\
C5 & 1.341 & 54.4 & 40.3 & 31.2 \\
C6 & 1.0473 & 59.5 & 44.1 & 34.0 \\
C7 & 1.0022 & 60.4 & 44.8 & 34.6 \\
C8 & 1.3332 & 53.5 & 39.7 & 30.6 \\
C9 & 1.3657 & 54.3 & 40.2 & 31.1 \\
\hline \hline
\end{tabular}

\section{PROBABILISTIC RELIABILITY ASSESSMENT WITH TVTR}

\section{A. Reliability evaluation modelling technique}

The proposed reliability assessment framework is based on Sequential Monte Carlo Simulation technique (SMCS). Monte Carlo techniques are used to represent the random failures with probability distributions and thus better approximate the solution to problems $[17,18]$. The approximate solution results in an error that is less than a given value with a certain probability known as the coefficient of variance $(\mathrm{CoV})$. The SMCS approach used in this paper is similar to that described in [17]. This approach is more realistic as it can model all the contingencies (e.g. loss of line(s), generator(s), thermal constraints) and operating characteristics inherent in Power systems components and operational behavior. Therefore, the duration of failures lasting more than one hour can be simulated capturing their effect on cable aging. In order to evaluate the system performance results are in the form of computing appraisal indices (i.e. reliability indices) indicating the loss of expected energy (LOEE), the loss of load expectation (LOLE) and the reliability risk of ageing (RCAI) indices. The LOLE is the number of times (in hours) the energy/load demand exceeds the supplied power from the grid and the LOEE (MWhr) is the amount of energy not served when this event occurs. The RCAI is an additional index that is proposed in order to record the expected ageing occurred on the cables and it is explained in section $\mathrm{C}$.

\section{B. Modelling of time varying thermal ratings (TVTR)}

In the distribution system, equipment interconnections are made between one or more UGC, at a high electrical potential by connection to available feeder stations at regular distances. The feeder stations are supplying the total demand for any given period.
The thermal properties limit the utilization levels of power system assets and when the thermal limits are exceeded severe ageing may occur depending on the equipment type as well as the level of exceedance. In order to be able to evaluate the level of exceedance the paper exploits the effect of TVTR modelling of the cables taking into account the changes of soil temperature in order to identify the reliability improvement of the system by reducing the LOLE.

In this paper, static thermal ratings (STR) refer to a system that operates on a thermal limitation based on assuming the worst soil conditions $\left(16^{\circ} \mathrm{C}\right.$ maximum soil temperature $)$ and $90^{\circ} \mathrm{C}$ conductor temperature. The seasonal thermal rating (SeTR) scenario considers the power network operated based on thermal limitations accounting for the seasonal variation of the soil temperatures, with winter (weeks 1-8 \& 44-52) being $9^{\circ} \mathrm{C}$, summer (weeks $18-30$ ) being $16^{\circ} \mathrm{C}$ and spring/fall (weeks 9-17 \& 31-43) being $11^{\circ} \mathrm{C}$ of a simulation year. The TVTR simulations consider the soil temperatures separately for each hour of a simulation year. Due to unavailability of soil temperature data, the change in soil temperature is generated based on the load and the seasonal temperatures. Fig.2 presents a snapshot of the time varying soil temperatures against the simulation periods. It illustrates the soil temperatures used for the study.

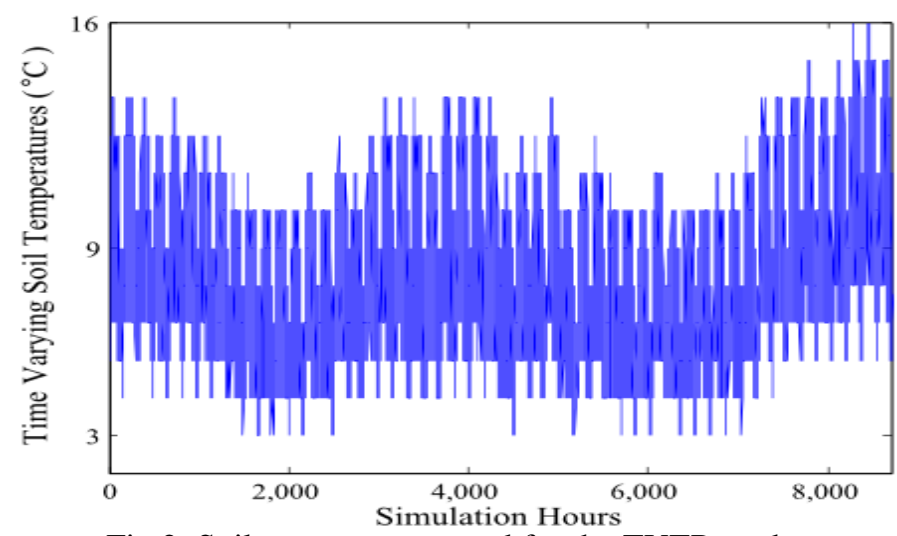

Fig.2: Soil temperatures used for the TVTR study

Therefore, the TVTR is carried out by the hourly periodic update of each of the branch current ratings along the course of the SMCS process which is performed using the following steps:

1. Initialize simulation (i.e. time is set to $t=1$ hour) by considering all cable conductor resistance temperatures being equal to the soil temperature (i.e. $\theta_{c}^{i n}=\theta_{s}$ ).

2. Calculate the thermal rating of the cables using equation (1) and assuming $\theta_{c}^{i n}$ as initial conductor temperature.

3. AC power flow is used to calculate the network currents based on the hourly load profile. Then using the calculated currents the new cable conductor temperatures $\left(\theta_{c}^{n e w_{-} i}\right.$ ) are computed by reconfiguring the (1). This process occurs iteratively till the temperature difference 
between two consecutive iterations is less than $1 \%$ of the final calculated temperature.

4. The results of the final AC power flow from step 3 are used to evaluate the network performance (by recording LOLE, LOEE and RCAI) for the simulation hour.

5. The next simulation hour is set $(t=t+1)$ and the process is repeated from step 3 to 5 till the end of the simulation period ( 8736 hours).

The number of years that the analysis is performed is determined by the $\mathrm{CoV}$ and 0.2 is used for the analysis discussed in this paper. The flowchart in Fig. 3 summarises the methodology described above.

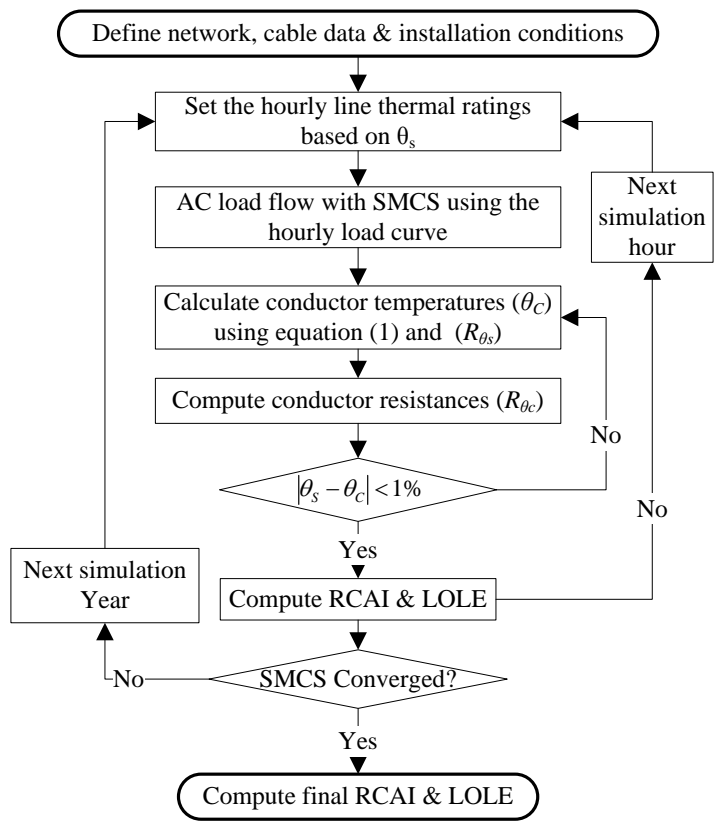

Fig.3: Modelling methodology

\section{Risk of cable ageing index - RCAI}

In this paper the European standard EN 1050 [12] that evaluates the risk by considering the product of the damage caused by an incident and its probability is implemented. In particular, the risk of cable ageing index considers the damage caused by the joule losses and the incident probability of LOLE. The RCAI is used to quantify the risk of ageing by accounting for the joule losses dissipated as heat for conductor temperatures above $50^{\circ} \mathrm{C}$.

The LOLE is multiplied by the mean joule losses recorded only for instances when the current flow causes the conductor temperature to hit $50^{\circ} \mathrm{C}$ and higher in calculating the RCAI. For most UGCs, critical temperature operation is considered at temperatures $50^{\circ} \mathrm{C}$ and above as a drying out of the backfill can occur and the $\vartheta_{c}$ can exceed the permissible temperatures. The RCAI implemented by multiplying LOLE of the network by the mean joule losses recorded for each cable when current flows raised the conductor temperature from $50^{\circ} \mathrm{C}$ and above. RCAI is calculated as described in equation (2) where, $I$ refers to the line current (amperes), $\mathrm{R}_{\mathrm{C}(\mathrm{t})}$ is the hourly conductor resistance when the cable is operating at critical temperature. The unit of the RCAI is in $\mathrm{kW}$-hours per loss of load occurrence.

$$
R C A I=I^{2} R_{C(t)} \times(\mathrm{LOLE})
$$

Consequently the increased losses will be resulted due to the increased current and resistance operation while the reduction in LOLE indicates more emergency loading conditions since loss of load is occurring when the cables are loaded to their maximum capacity.

\section{SIMULATION RESULTS AND ANALYSIS}

Studies in this paper are concerned with dynamic loading conditions of the cables and focus on the impact that different thermal loading have on the network performance as well as on the cable ageing. A small thermal time constant is considered in order to avoid transient temperature variations and simplify the overall network analysis. This means that during the simulations the change in cable loading results in immediate increase in cable temperature. This results in more conservative ageing analysis as in reality the cable temperature will be gradually increased to the steady-state value. The results of the analysis considering the three different thermal rating models with SMCS are shown in Table III. The implementation of more advanced thermal modelling (TVTR) results in a substantial improvement of the system reliability indices with a fivefold reduction of loss of expected energy compared to the standard model (STR).

TABLE III

NETWORK PERFORMANCE WITH SMCS FOR THE EXAMINED C7 THERMAL MODELS

\begin{tabular}{|l|l|l|l|}
\hline \hline Index & STR & SeTR & TVTR \\
\hline LOLE (hrs/yr.) & 5 & 3 & 2 \\
\hline \multirow{2}{*}{ LOEE (MWhr/yr.) } & $\begin{array}{l}4.96 \mathrm{pu} \\
(0.3624)\end{array}$ & $\begin{array}{l}2.28 \mathrm{pu} \\
(0.1671)\end{array}$ & $\begin{array}{l}1 \mathrm{pu} \\
(0.073)\end{array}$ \\
\hline \hline
\end{tabular}

The thermal model described by (1) considering the three different thermal rating methods is used along with the methodology describe in Fig. 3 to compute losses and ageing for improved asset management. The RCAI is used to compare the performance of three critical cables (L2, L19 and L23 respectively) of the test network considering their resistances and loading levels and durations.

Table IV illustrates the calculated values of RCAI for the critical cables considering the different thermal rating models (STR, SeTR and TVTR). The RCAIs for the nine aforementioned ducting conditions are evaluated considering separate network analyses under both contingent and intact network conditions. The intact network analyses indicate the ageing risks recorded due to network loading (i.e. when there is no loss of load in the network). The contingent network results indicate the ageing occurred on the cables due to the increased operating emergency loading durations during random cable failures.

From Table IV results the increase in losses for cable L2 can be seen for all different ducting installations. This is the result of the increased power that is delivered to the customers (i.e. reduced LOLE) and therefore the increased duration at 
higher temperatures during contingent scenarios. However, when C6 or C7 ducting type installation is used the losses for cables L19 and L23 are reduced even when TVTR is implemented.

From Table IV an increase in RCAI for the examined cables can be observed when comparing the intact with the contingent network analyses. This is true for all different ducting installations. The increase in RCAI during the contingent network is the result of the increased power delivered to the customers during the emergency conditions (i.e. reduced LOLE) and therefore the increased duration of the cables at higher operating temperatures as well as the increased losses. However, when C6 and C7 ducting type installations are used then the network develops the less ageing on the three critical loaded cables. This indicates that the pressure pipe type cables have increased performance at high operating temperatures when compared to the other ducting systems. Consequently, the importance of the choice of duct installation condition is apparent for critical network lines that are expected to experience more frequent operation at temperatures above $50^{\circ} \mathrm{C}$. It is however important to consider the cost of ducting in order to evaluate the benefit of the complete cabling system can offer to the overall network performance.

TABLE IV

RCAI OF CABLES L2, L19 AND L23 FOR INTACT AND CONTINGENT NETWORK

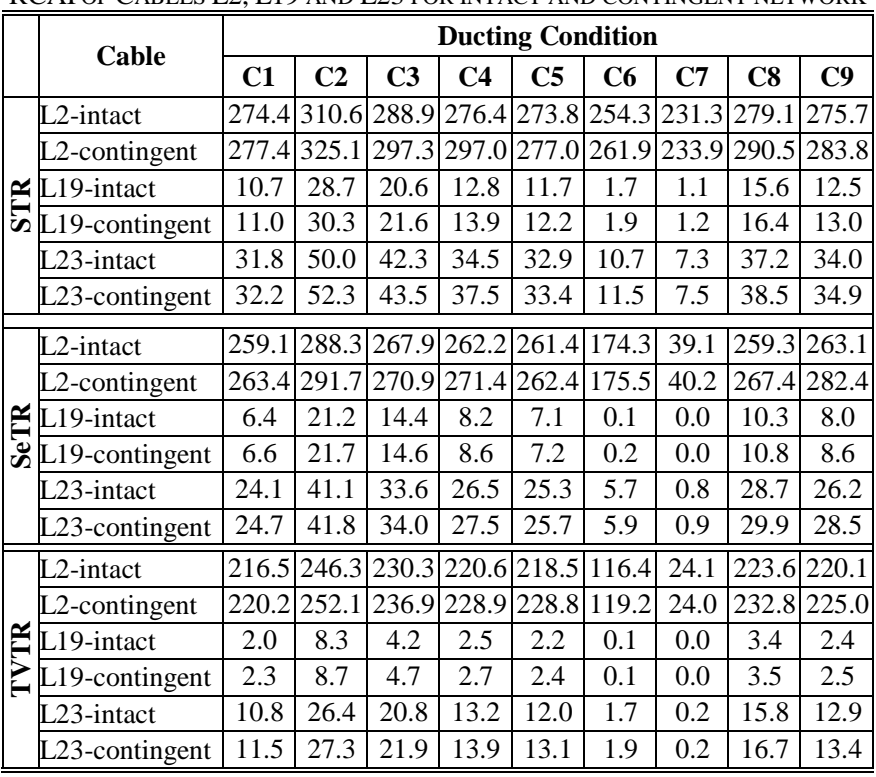

By observing the results in Table IV among the different thermal rating models (STR, SeTR, TVTR) a reduction in expected cable ageing for the same network loading curve is achieved when the more advanced thermal rating models are used. The reduction is more intense when the TVTR is used compared to the SeTR. The minimum expected RCAI value is developed for the 'intact' network and TVTR scenario. This is expected to result into very slower aging process explained by Miner's theory which suggests that ageing cumulates over a components life in such a way that short periods of severe degradation may be overcompensated by long periods of mild degradation [17].

Fig.4 shows the operational temperature profile of the critical network cables in form of bar charts for a simulation year when different types of ducting are considered. For each of the critical network cables the nine duct installation conditions described previously are illustrated. Each ducting is represented by group of two bars the top showing the temperature profile during SeTR while the bottom one showing the TVTR.
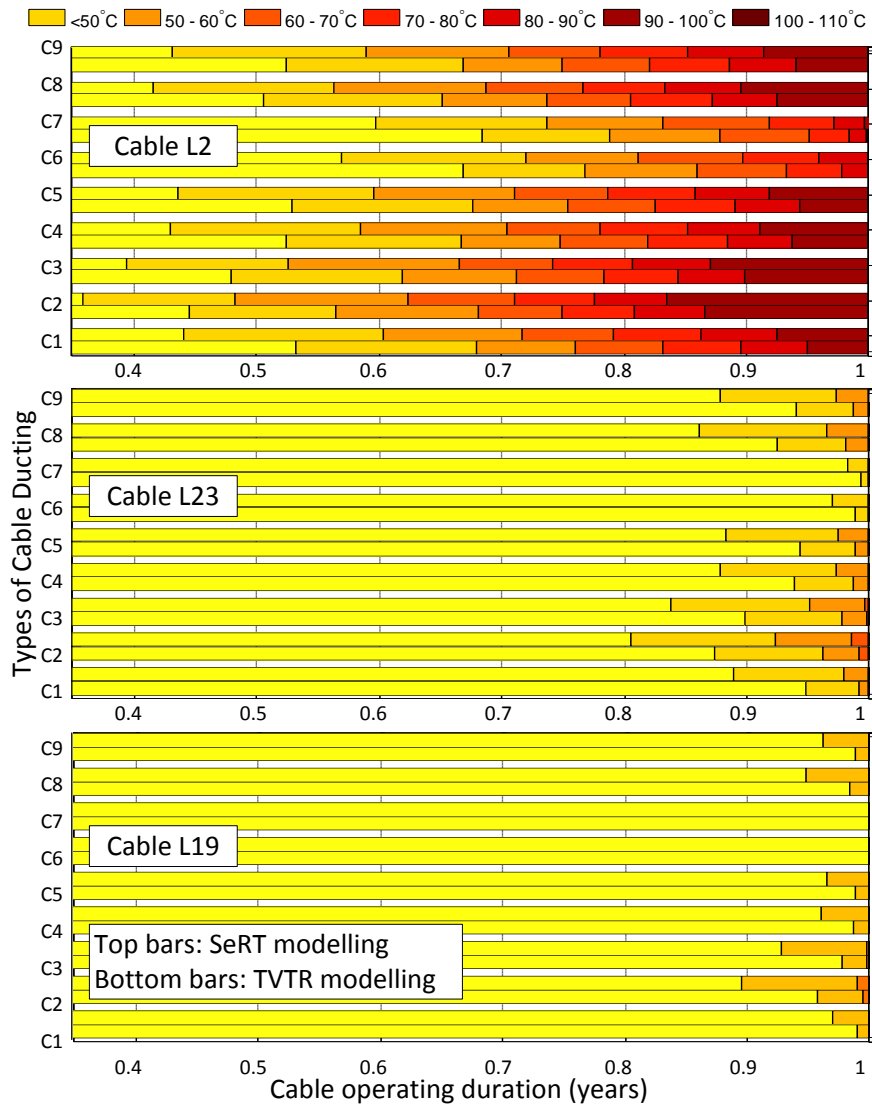

Fig.4: Operating temperature profiles of the network's critical cables

The operating temperature profiles if Fig. 4 indicate that the RCAI of L19 and L23 cables are mainly developed during normal operating conditions as the cable operating temperature does not exceed the $90{ }^{\circ} \mathrm{C}$ and it operates at above $80{ }^{\circ} \mathrm{C}$ for a very small period of time during a year. This is also in agreement with the data provided in Table IV. The operation temperature profile of the L2 cable as opposed to the other two critical cables indicates an operating duration of the cable at elevated temperatures (above $90{ }^{\circ} \mathrm{C}$ ) in most of the ducting types modelled. This elevated temperature operation is considerable in most of the ducting types apart the pressure pipe type ducting (C6 and C7).

The results in Fig. 4 indicate that the L2 cable is operating at elevated temperatures in all three different thermal rating models (STR, SeTR, and TVTR), however the smallest duration occurs when the TVTR is considered. However, even then the ageing of L2 cable is more considerable when 
compared to the other cables and justifies a more expensive ducting installation for L2. This will reduce the ageing of the cable reducing the failure rate of $\mathrm{L} 2$ cable but also will increase its repair rate due to the increased complexity of the ducting.

\section{CONCLUSIONS}

This paper presents a method for network analysis that incorporates the cable properties in order to capture the ageing (RCAI) that is occurring on the individual cables of the network. The 33 bus IEEE RTS network is utilised for the network analyses assuming that all network lines are cables.

This network analyses indicated that there are three critical cables that experienced thermal stresses in the 33 bus IEEE RTS network the L2, L19, and L23 cables. When the L19 and L23 are considered the ageing stresses are not very different from the other cables as they operate for a very short period at the range of $80^{\circ} \mathrm{C}$ to $90^{\circ} \mathrm{C}$ temperatures with zero instances above $90^{\circ} \mathrm{C}$. In the contrary $\mathrm{L} 2$ cable is loaded at $110^{\circ} \mathrm{C}$ (Fig. 3) for long duration indicating an excessive ageing when compared to the other cables of the network.

In order to reduce the ageing of the L2 cable more advanced ducting could be used. In particular the C6 will half the ageing of the cable while the $\mathrm{C} 7$ type will reduce the ageing of the most critical network cable by tenfold. The fiber ducts (C2 and C3) installations appear to have the worst effect on cable ageing.

Future work will focus on varying cable installation depths, cable types, consideration of repair rates and estimation of thermal ageing based on line temperatures and Joule losses for each cabling system so as to ascertain the optimal cable for specific needs during planning.

\section{REFERENCES}

[1] F. de Leon and G. J. Anders, "Effects of Backfilling on Cable Ampacity Analyzed With the Finite Element Method,", IEEE Transactions on Power Delivery, vol. 23, pp. 537-543, 2008.

[2] Calculation of The Continous Current Rating of Cables (100\% Load factor), 287, IEC (2006), IEC Standard Publ., $2^{\text {nd }}$ ed.

[3] C.-h. Lei, G. Liu, and Y.-g. Liu, "An accuracy assessment method of calculating cable conductor temperature through surface temperature and actual loading current," IEEE International Symposium on Electrical Insulation (ISEI), 2010, pp. 1-3.

[4] L. Mariut, E. Helerea, G. Lungoci, and S. Abagiu, "Thermal analysis of underground power cables-A monitoring procedure," International
Conference on Applied and Theoretical Electricity (ICATE),, 2012, pp. $1-6$.

[5] Z. Wei, L. Hong-Jie, L. Chongxin, and T. Kee Choon, "A Technique for Assessment of Thermal Condition and Current Rating of Underground Power Cables Installed in Duct Banks," Power and Energy Engineering Conference (APPEEC), Asia-Pacific 2012, pp. 1-6.

[6] A. Hiranandani, "Calculation of conductor temperatures and ampacities of cable systems using a generalized finite difference model," IEEE Transactions on Power Delivery, vol. 6, pp. 15-24, 1991.

[7] R. Olsen, J. Holboell, and U. S. Gudmundsdottir, "Electrothermal Coordination in Cable Based Transmission Grids," IEEE Transactions on Power Systems, vol. 28, pp. 4867-4874, 2013.

[8] R. S. Olsen, J. Holboll, and U. S. Gudmundsdottir, "Dynamic temperature estimation and real time emergency rating of transmission cables," IEEE Power and Energy Society General Meeting, 2012, pp. 18 .

[9] R. Billinton and D. Huang, "Aleatory and Epistemic Uncertainty Considerations in Power System Reliability Evaluation," Proceedings of the 10th International Conference on Probabilistic Methods Applied to Power Systems, PMAPS '08., pp. 1-8, 2008.

[10] R. Allan and R. Billinton, "Power system reliability and its assessment. I. Background and generating capacity," Power Engineering Journal, vol. 6, pp. 191-196, 1992.

[11] A. Underbrink, "Risk Analysis in Distribution and Transmission Networks," PMAPS 2006. International Conference on in Probabilistic Methods Applied to Power Systems, 2006, pp. 1-4.

[12] P. Carer, "Probabilistic methods used in asset management for MV electrical equipment at EDF," PMAPS 2006. International Conference on Probabilistic Methods Applied to Power Systems, 2006, pp. 1-5.

[13] D. Roberts, P. Taylor, and A. Michiorri, "Dynamic thermal rating for increasing network capacity and delaying network reinforcements," IETCIRED Seminar on SmartGrids for Distribution Systems, 2008, pp. 1-4.

[14] M. E. Baran and F. F. Wu, "Network reconfiguration in distribution systems for loss reduction and load balancing," IEEE Transactions on Power Delivery,, vol. 4, pp. 1401-1407, 1989.

[15] R. Billinton, W. Li, Reliability Assessment of Electrical Power Systems Using Monte Carlo Methods: Springer, 1994.

[16] R. E. Brown, Electric Power Distribution Reliability, Second ed. vol. 31: CRC Press, 2008

[17] M. A. Miner, "Cumulative Damage in Fatigue," Journal of Appl. Mechanics, p. 5, 1945.

[18] C. T-Chakonta, K. Kopsidas, 'Assessing the Value of Employing Dynamic Thermal Rating on System-wide Performance". Proceedings of the 10th Innovative Smart Grid Technologies (ISGT Europe), Manchester, UK, 2011, pp. 1-8.

[19] L. Lindstrong, "Evaluating impact on ampacity according to IEC-60287 regarding thermally unfavourable placement of power cables," M.S. Thesis, School of Elect. Eng., KTH Royal Institute of Technology, Stokholm, Sweden, 2011.

[20] G. Lloyd, R.G. Bouchet, L. Zhou, C. An, "Real-Time thermal rating and active control improved distribution network utilisation," Proceedings of $47^{\text {th }}$ international universities Power Engineering Conference (UPEC), 2012, pp 1-6 